\title{
Tyk2 as a target for immune regulation in human viral/bacterial pneumonia
}

\author{
Johanna Berg ${ }^{1,2,8}$, Katja Zscheppang ${ }^{1,8}$, Diana Fatykhova', Mario Tönnies ${ }^{3}$, \\ Torsten T. Bauer ${ }^{3}$, Paul Schneider ${ }^{4}$, Jens Neudecker ${ }^{5}$, Jens C. Rückert ${ }^{5}$, \\ Stephan Eggeling ${ }^{6}$, Maria Schimek $^{6}$, Achim D. Gruber ${ }^{7}$, Norbert Suttorp ${ }^{1}$, \\ Stefan Hippenstiel ${ }^{1}$ and Andreas C. Hocke ${ }^{1}$
}

Affiliations: ${ }^{1}$ Dept of Internal Medicine/Infectious Diseases and Respiratory Medicine, Charité - Universitätsmedizin Berlin, Berlin, Germany. ${ }^{2}$ Dept of Biotechnology, Technical University of Berlin, Berlin, Germany. ${ }^{3} \mathrm{HELIOS}$ Clinic Emil von Behring, Dept of Pneumology and Dept of Thoracic Surgery, Chest Hospital Heckeshorn, Berlin, Germany. ${ }^{4}$ Dept for General and Thoracic Surgery, DRK Clinics, Berlin, Germany. ${ }^{5}$ Dept of General, Visceral, Vascular and Thoracic Surgery, Universitätsmedizin Berlin, Berlin, Germany. ${ }^{6}$ Dept of Thoracic Surgery, Vivantes Clinics Neukölln, Berlin, Germany. ${ }^{7}$ Dept of Veterinary Pathology, College of Veterinary Medicine, Freie Universität Berlin, Berlin, Germany. ${ }^{8}$ Both authors contributed equally.

Correspondence: Andreas Hocke, Charité - Universitätsmedizin Berlin, Dept of Internal Medicine/Infectious Diseases and Respiratory Medicine, Charitéplatz 1, 10117 Berlin, Germany. E-mail: andreas.hockelacharite.de

@ERSpublications

Tyk2 inhibition might be a strategy to sustain endogenous GM-CSF levels in severe viral/bacterial pneumonia http://ow.ly/Owv130aWr6Z

Cite this article as: Berg J, Zscheppang K, Fatykhova D, et al. Tyk2 as a target for immune regulation in human viral/bacterial pneumonia. Eur Respir J 2017; 50: 1601953 [https://doi.org/10.1183/13993003.019532016].

ABSTRACT The severity and lethality of influenza A virus (IAV) infections is frequently aggravated by secondary bacterial pneumonia. However, the mechanisms in human lung tissue that provoke this increase in fatality are unknown and therapeutic immune modulatory options are lacking.

We established a human lung ex vivo co-infection model to investigate innate immune related mechanisms contributing to the susceptibility of secondary pneumococcal pneumonia.

We revealed that type I and III interferon (IFN) inhibits Streptococcus pneumoniae-induced interleukin (IL)-1 $\beta$ release. The lack of IL-1 $\beta$ resulted in the repression of bacterially induced granulocyte-macrophage colony-stimulating factor (GM-CSF) liberation. Specific inhibition of IFN receptor I and III-associated tyrosine kinase 2 (Tyk2) completely restored the S. pneumoniae-induced IL-1ß-GM-CSF axis, leading to a reduction of bacterial growth. A preceding IAV infection of the human alveolus leads to a type I and III IFN-dependent blockade of the early cytokines IL-1 $\beta$ and GM-CSF, which are key for orchestrating an adequate innate immune response against bacteria. Their virally induced suppression may result in impaired bacterial clearance and alveolar repair.

Pharmacological inhibition of Tyk2 might be a new treatment option to sustain beneficial endogenous GM-CSF levels in IAV-associated secondary bacterial pneumonia.

This article has supplementary material available from erj.ersjournals.com

Received: Oct 052016 | Accepted after revision: April 072017

Support statement: The study was funded by the German Ministry of Education and Research (BMBF - PROGRESS) to A.C. Hocke (C8) and by the German Research Foundation (DFG SFB-TR84) to N. Suttorp (B1), A.D. Gruber (Z1b), A. C. Hocke (Z1a) and to A.C. Hocke and S. Hippenstiel (B6). Funding information for this article has been deposited with the Crossref Funder Registry.

Conflict of interest: Disclosures can be found alongside this article at erj.ersjournals.com

Copyright OERS 2017 


\section{Introduction}

Severe pneumonia causes high levels of mortality worldwide, which have remained almost unchanged since the introduction of antibiotics [1, 2]. Influenza A virus (IAV) and Streptococcus pneumoniae, especially in subsequent co-infections, account for a majority of the fatal outcomes [3]. Considering the fatalities resulting from secondary bacterial pneumonia, the threat of future IAV outbreaks and the increasing bacterial resistance towards antibiotics [4], it is pivotal to apprehend the molecular interplay between viruses, bacteria and pulmonary target cells to enable innovative adjunctive therapies beyond pathogen-directed clinical approaches.

Previous studies in mice indicate that mechanisms accounting for increased severity of secondary bacterial co-infection include IAV-induced alterations of phagocyte functions, epithelial damage which increases bacterial adherence or alteration of immune system components [4]. In particular, IAV-induced type I and II interferons (IFNs) are suspected to modulate innate immune responses such as chemokine (C-X-C motif) ligand [5] chemokines, interleukin (IL)-17-producing $\gamma \delta$ T-cells or bacterial clearance in secondary bacterial infections $[6,7]$. However, the interference of IAV-induced IFN in the recognition of secondary bacterial pathogens in human lung tissue is completely unknown.

In vitro studies on monocytes and macrophages revealed that IFN may interfere with central proinflammatory cytokine pathways such as the inflammasome, thereby inhibiting IL-1 $\beta$ production [8-10]. In turn, IL-1 $\beta$ seems to be critical for survival in S. pneumoniae infection or in post-IAV Staphylococcus aureus pneumonia in mice $[11,12]$. The cellular source, molecular mechanism and its role for induction of subsequent cytokine responses in human lungs are still unknown.

Besides IL-1 $\beta$, IFN alters the production of another central factor for pulmonary inflammation control, the granulocyte-macrophage colony-stimulating factor (GM-CSF) [13, 14]. In mice infected with IAV (H1N1), GM-CSF enhanced the amount and resistance of alveolar macrophages, as well as the recruitment and activation of dendritic cells, both significantly contributing to survival rates [15-18]. Likewise, in mice mortality rates were improved due to enhanced bacterial killing by alveolar macrophages of $S$. pneumoniae or group B streptococci, and even infection with Gram-negative Klebsiella pneumoniae showed less apoptosis and alveolar leakage after GM-CSF treatment [19-21]. Moreover, the first clinical trials using GM-CSF for adjunctive treatment in acute lung injury or adult respiratory distress syndrome (ARDS) underscore the therapeutic potential ascribed to this molecule $[22,23]$.

Therefore, we established an ex vivo human lung co-infection model with IAV and S. pneumoniae to investigate the cellular regulation of these cytokines in the genuine human alveolar compartment. Our study demonstrates on a cellular level how IAV-induced IFN impedes S. pneumoniae-related IL-1 $\beta$ liberation, thereby suppressing GM-CSF production in the human alveolus. Moreover, by inhibition of IFN receptor-associated tyrosine kinase 2 (Tyk2), we offer a potential pharmacological treatment option to restore the virally repressed immune response against secondary bacterial infection.

\section{Materials and methods}

Methods

Detailed information is outlined in the online supplementary material.

\section{Human lung tissue}

Normal peripheral human lung tissue was freshly obtained from patients suffering from bronchial carcinoma. The study was approved by the ethics committee of the Charité - Universitätsmedizin Berlin (projects EA2/050/08 and EA2/023/07); written informed consent was obtained from all patients. The tissue was stamped into small cylinders $(3 \times 8 \times 8 \mathrm{~mm})$ and incubated as described [24].

\section{Isolation of primary human alveolar macrophages and alveolar epithelial cells}

Alveolar macrophages were isolated by repeated perfusion of the human lung tissue with Hanks' balanced salt solution (HBSS) and seeded in six-well plates $\left(1 \times 10^{6}\right.$ cells) and cultured in RPMI 1640 medium for $2-$ 4 days. Type II alveolar epithelial cells (AECs) were isolated using a modified method described by ELBERT et al. [25]. Briefly, after removal of alveolar macrophages, human lung tissue was finely minced and digested using trypsin type I and DNase. The digested tissue was serially filtered through sterile gauze strainers. Cells were centrifuged and incubated for $1.5 \mathrm{~h}$ in 1:1 HBSS:hybridoma-serum-free medium for differential adherence of alveolar macrophages. Afterwards, the cell fraction was collected, centrifuged and layered on a Pancoll (PanBiotech, Aidenbach, Germany) discontinuous gradient. After centrifugation, cells at the interfacial layer were collected, washed with HBSS and seeded in a 24-well plate and cultured in RPMI 1640. 
Viral and bacterial strains

The human seasonal IAV strain A/Panama/2007/1999 (Pan/99(H3N2)) was propagated as described by Weinheimer et al. [26]. Two strains of S. pneumoniae, the encapsulated strain D39 serotype 2 (NCTC7466) and a clinical isolate serotype 3 (ST3, SN35209) were used and cultured as described [27].

\section{Infection and stimulation of human lung tissue and cells}

For infection experiments lung cultures were first inoculated with IAV $\left(1 \times 10^{6} \mathrm{PFU}\right)$ for $24 \mathrm{~h}$ as well as for a further $16 \mathrm{~h}$ with $S$. pneumoniae (D39 or ST3, $1 \times 10^{6} \mathrm{CFU} \cdot \mathrm{mL}^{-1}$ ) as indicated. Culture medium containing either recombinant IFN $-\beta,-\gamma,-\lambda_{1}$, a combination of IFN- $\beta$ and $-\gamma$ or a combination of IFN- $\beta$, $-\gamma$ and $-\lambda_{1}\left(100 \mathrm{U} \cdot \mathrm{mL}^{-1}\right.$ each), tumour necrosis factor (TNF)- $\alpha\left(100 \mathrm{U} \cdot \mathrm{mL}^{-1}\right)$, IL-1 $\beta\left(10 \mathrm{ng} \cdot \mathrm{mL}^{-1}\right)$, anakinra $\left(1 \mu \mathrm{g} \cdot \mathrm{mL}^{-1}\right)$ or PRT2070 (cerdulatinib) $(1 \mu \mathrm{M})$ was injected into lung explants at indicated time points. Control explants received equivalent amounts of culture medium containing PBS. AEC II and alveolar macrophages were infected with S. pneumoniae D39 (1 multiplicity of infection (MOI)) for $16 \mathrm{~h}$. Additionally, AEC II were stimulated with IL-1 $\beta\left(5 \mathrm{ng} \cdot \mathrm{mL}^{-1}\right)$ for $16 \mathrm{~h}$. For alveolar macrophage supernatant experiments, AEC II were pretreated with anakinra $\left(1 \mu \mathrm{g} \cdot \mathrm{mL}^{-1}\right)$ for $4 \mathrm{~h}$ and supernatant of alveolar macrophages (16 h S. pneumoniae D39, 1 MOI), was added and incubated for $20 \mathrm{~h}$.

\section{Results}

Human lung tissue model for ex vivo co-infection of IAV and S. pneumoniae

We established a co-infection model using ex vivo cultivated human lung tissue inoculated with control medium or Pan/99(H3N2) for $24 \mathrm{~h}$ (online supplementary figure S1A and S1B). Additional samples were subsequently challenged with $S$. pneumoniae D39 for a further $16 \mathrm{~h}$ (online supplementary figure S1C and $\mathrm{S} 1 \mathrm{D})$. As previously shown, exclusively AEC II were infected by IAV as indicated by pro-surfactant protein C co-localization [26]. S. pneumoniae D39 was detected closely attached to the cell surface of AEC I and AEC II as well as alveolar macrophages independent of prior IAV infection (online supplementary figure S1D).

\section{IAV-induced type I, II and III IFN show unchanged expression during co-infection with S. pneumoniae}

IFNs are assumed to play a major role in susceptibility to secondary bacterial infection; however, this is still unexamined for human lung tissue. Therefore, we first analysed the secretion of different IFN types after single and co-infection in the lung tissue supernatants. Pan/99(H3N2) significantly induced the release of IFN- $\alpha_{2}$ and IFN- $\beta$ (type I), IFN- $\gamma$ (type II) and IFN- $\lambda_{1}$ (type III), whereas $S$. pneumoniae D39 showed no IFN induction at all (figure $1 \mathrm{a}-\mathrm{d}$ ). The secretion pattern of all IFN was not significantly changed in viral and bacterial co-infection, demonstrating that $S$. pneumoniae has no effect on IFN regulation, which might pave the way for a compromised secondary host defence against the bacteria.

\section{IAV and IFN interfere with the S. pneumoniae-induced IL-1ß-GM-CSF axis in human lungs}

The induction of cytokines and chemokines plays an important role in the initiation of innate immune responses to control viral and bacterial infections [28]. Accordingly, studies in mice revealed that induction of type I and II IFN during primary nonlethal influenza virus infection complicates the defence against a range of bacterial pathogens $[6,7]$. Nevertheless, their role with regard to human lung co-infection is so far unknown. We first examined the influence of IAV on the regulation of typical pneumococcal-induced factors in human lung supernatants. S. pneumoniae D39 infection significantly induced all tested cytokines, but no changes were found in co-infection of IL-6, IL-8, IL-10 and TNF- $\alpha$ in the presence of IAV (online supplementary figure S2A-D). However, the preceding IAV infection significantly reduced S. pneumoniae D39 induction of IL-1 $\beta$ and GM-CSF (figure $2 \mathrm{a}$ and b), which was confirmed for the clinical ST3 isolate (online supplementary figure S2E and F). Since in vitro studies indicate that IFN might interfere with IL-1 $\beta$ and GM-CSF induction, we tested whether IFN in human lung tissue can mimic IAV-induced suppression of IL-1 $\beta$ and GM-CSF $[8-10,13,14]$. Next to single and co-infection with Pan/99(H3N2) and S. pneumoniae D39, we replaced IAV with IFN- $\beta$ and IFN- $\gamma$ treatment for the same time course and compared the liberated amount of IL-1 $\beta$ and GM-CSF. In line with IAV infection, IFN significantly blocked $S$. pneumoniae-induced IL-1 $\beta$ and GM-CSF synthesis to a similar degree (figure $2 c$ and d). Interestingly, a study by CAKAROVA et al. [29] showed that expression of alveolar epithelial GM-CSF in mice depends on induction by TNF- $\alpha$. We observed that compared to IL- $1 \beta$ (figure $2 \mathrm{a}$ and $\mathrm{c}$ ), levels of pneumococcal-induced TNF- $\alpha$ remained unchanged during IAV infection or treatment with IFN (online supplementary figure S3). Hence, we hypothesised that in human lung tissue the expression of GM-CSF is dependent on IL-1 $\beta$ rather than TNF- $\alpha$. Pretreatment of human lungs with the IL-1 receptor antagonist anakinra $(4 \mathrm{~h})$ prior to $16-\mathrm{h} S$. pneumoniae D39 infection or IL-1 $\beta$ stimulation significantly reduced GM-CSF expression (figure 2e). In contrast, TNF- $\alpha$ stimulation of human lungs was not sufficient for induction of GM-CSF (figure 2f). The induction of cyclo-oxygenase-2 in the same lungs served as a positive control for effective TNF- $\alpha$ stimulation (online supplementary figure S4A). 
a)

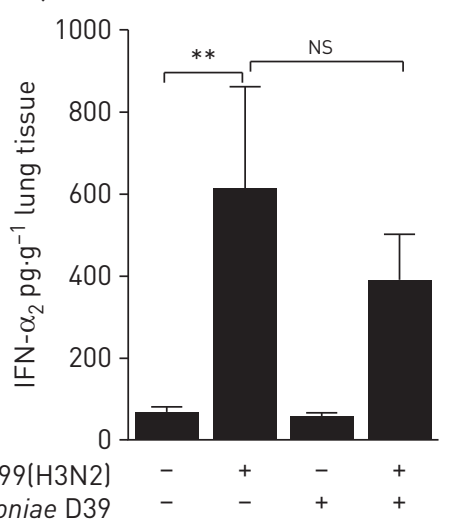

b)

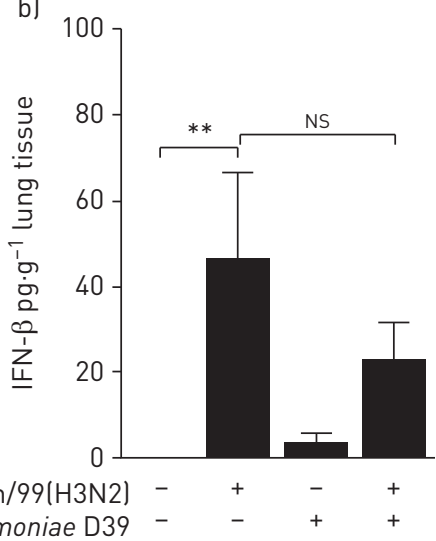

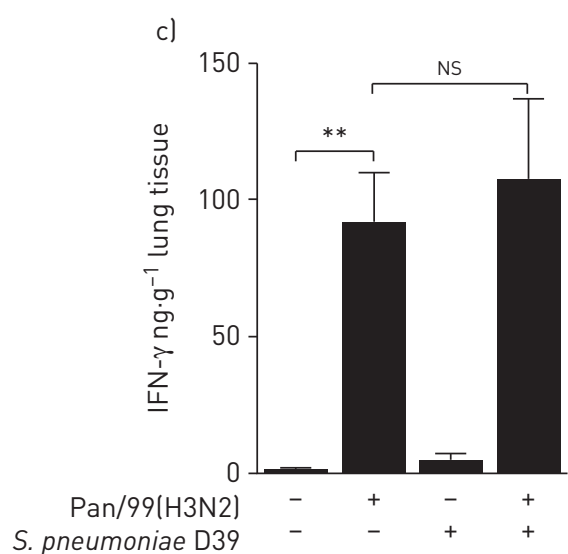

d)

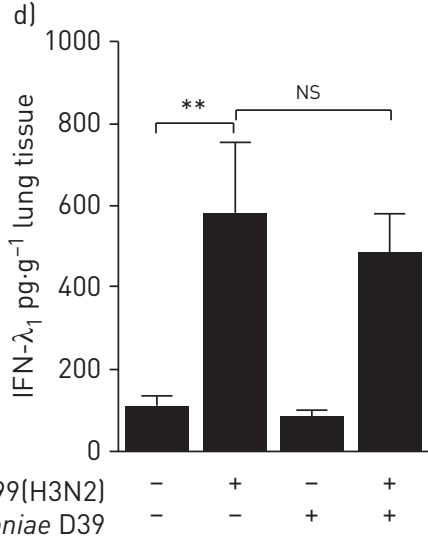

FIGURE 1 Interferon (IFN) production in co-infected human lung tissue. Lung explants were ex vivo mock infected or challenged with influenza A virus Pan/99(H3N2) $\left(1 \times 10^{6} \mathrm{PFU} \cdot \mathrm{mL}^{-1}\right)$. After $24 \mathrm{~h}$, dedicated explants were either infected with Streptococcus pneumoniae D39 $\left(1 \times 10^{6} \mathrm{CFU} \cdot \mathrm{mL}^{-1}\right)$ or mock infected. Supernatants were collected $16 \mathrm{~h}$ after pneumococcal infection and assayed for al type I IFN- $\alpha_{2}$; b) IFN- $\beta$; c) type II IFN- $\gamma_{i}$ and d) type III IFN- $\lambda_{1}$ release. Data are presented as mean \pm SEM of six donors within independent experiments. NS: nonsignificant. ${ }^{* *}: p \leqslant 0.01$.

In order to underscore the direct dependency of GM-CSF liberation on IL-1 $\beta$ production we determined the time course of both factors in S. pneumoniae-infected human lung tissue. Direct comparison of expression patterns revealed a time-shifted secretion beginning with considerable amounts of IL-1 $\beta$ after 4-6 h followed by GM-CSF after 8-16 h (online supplementary figure S4B). Taken together, these data suggest that the release of GM-CSF in human lungs is mainly dependent on IL- $1 \beta$ rather than TNF- $\alpha$.

\section{AEC II- and alveolar macrophage-derived IFN blocks IL-1B of alveolar macrophages leading to suppression of AEC II-expressed GM-CSF}

Our data indicate that IAV-induced IFNs blocked IL-1 $\beta$ release, finally leading to loss of GM-CSF production in human lungs. To further investigate the underlying cellular interplay of this cytokine regulation in viral and bacterial co-infection, we isolated alveolar macrophages and AEC II from fresh human lung tissue. Phenotype characterisation by immunofluorescence staining showed isolated alveolar macrophages positive for CD68, AEC II for pan-cytokeratin, and pro-surfactant protein C (online supplementary figures S5A and S5B). First, we investigated the release of IFN by IAV-infected AEC II and alveolar macrophages, demonstrating that both cell types produce IFN- $\alpha,-\beta$ and $-\lambda_{1}$, but IFN- $\gamma$ is mainly released by AEC II in the human alveolar compartment (figure $3 \mathrm{a}-\mathrm{d}$ ). In contrast, AEC II are negative for release of IL-1 $\beta$ after infection with $S$. pneumoniae D39 (figure 3e), but showed significant release of GM-CSF after IL-1 $\beta$ treatment. In line with stimulation of intact human lung tissue, $S$. pneumoniae failed to directly induce GM-CSF secretion in AEC II (figure 3f). In contrast, S. pneumoniae infection of alveolar macrophages led to a strong release of IL-1 $\beta$, but failed to induce GM-CSF expression (figure $3 \mathrm{~g}$ and h). Simultaneous treatment of alveolar macrophages with type I and II IFN was sufficient to suppress IL- $1 \beta$ production (figure $3 \mathrm{i}$ ), while TNF- $\alpha$ was not reduced in the same samples (online supplementary figure S6), mirroring the results obtained in intact lung tissue. 

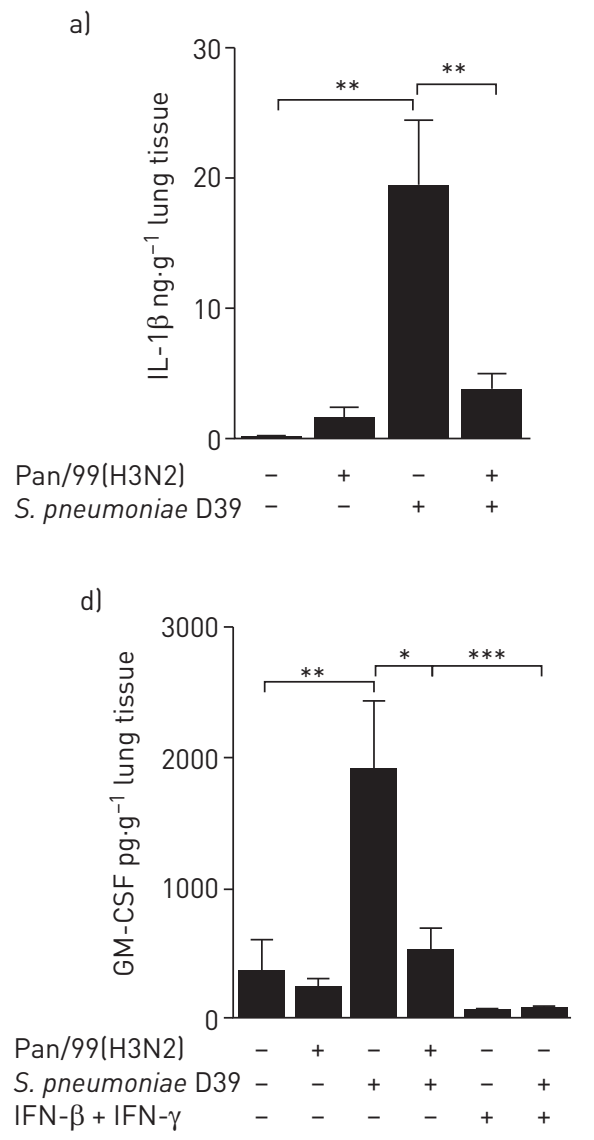

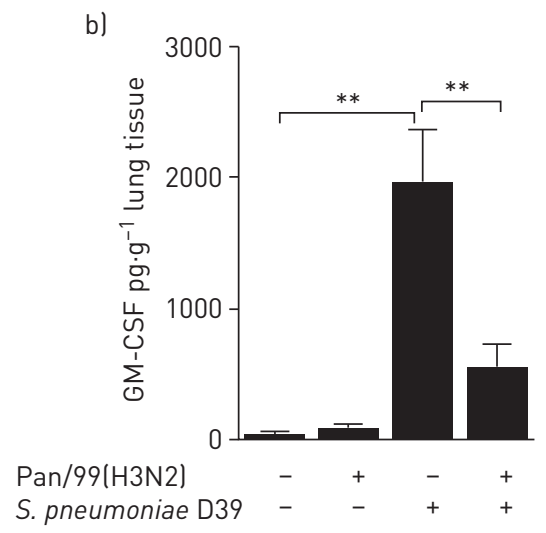

e)

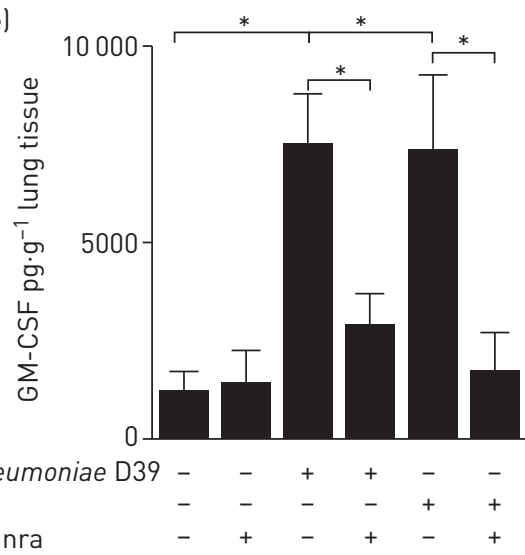

c)

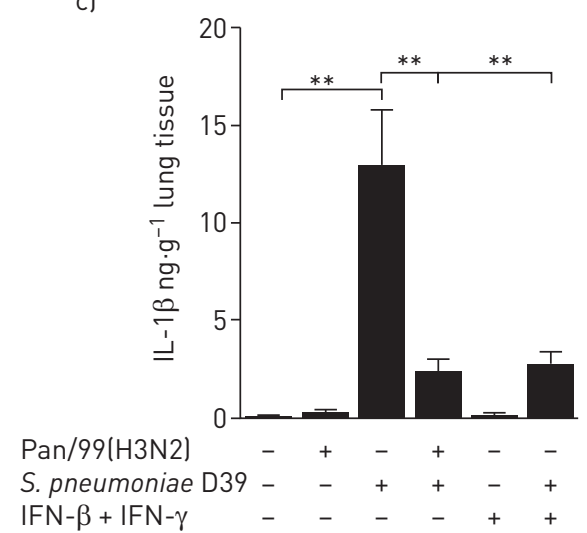

FIGURE 2 Co-infection with influenza A virus Pan/99(H3N2) (IAV) and treatment with interferons (IFN) inhibits the Streptococcus pneumoniae D39-induced interleukin (IL)-1 $\beta$-granulocyte-macrophage colony-stimulating factor (GM-CSF) axis in human lungs. Lung explants were ex vivo mock infected or challenged with (a and b) IAV $\left(1 \times 10^{6} \mathrm{PFU} \cdot \mathrm{mL}^{-1}\right)$ for $24 \mathrm{~h}$ or (c-e) a combination of IFN- $\beta$ and IFN- $\gamma\left(100 \mathrm{U} \cdot \mathrm{mL}^{-1}\right.$ each) for $16 \mathrm{~h}$. Afterwards, dedicated specimen were infected with the S. pneumoniae $\left(1 \times 10^{6} \mathrm{CFU} \cdot \mathrm{mL}^{-1}\right)$. Supernatants were collected $16 \mathrm{~h}$ after pneumococcal

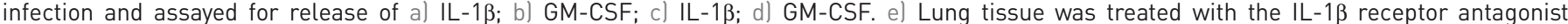
anakinra (1 ng. $\left.\mathrm{mL}^{-1}\right)$ or control medium. After $4 \mathrm{~h}$, indicated lung specimen were either mock infected, challenged with $S$. pneumoniae $\left(1 \times 10^{6} \mathrm{CFU} \cdot \mathrm{mL}^{-1}\right)$ or stimulated with recombinant IL-1 $\left(10 \mathrm{ng} \cdot \mathrm{mL}^{-1}\right)$ for $16 \mathrm{~h}$, and subsequently assayed for GM-CSF release. $\left.\mathrm{f}\right)$ Lung tissue was either mock stimulated or treated with tumour necrosis factor (TNF)- $\alpha\left(100 \mathrm{ng} \cdot \mathrm{mL}^{-1}\right)$ for $16 \mathrm{~h}$ in the presence or absence of anakinra $\left(1 \mathrm{ng} \cdot \mathrm{mL}^{-1}\right)$. After $4 \mathrm{~h}$, lung specimens were either mock infected or challenged with $\mathrm{S}$. pneumoniae $\left(1 \times 10^{6} \mathrm{CFU} \cdot \mathrm{mL}^{-1}\right)$ for $16 \mathrm{~h}$, and subsequently assayed for GM-CSF release. Data are presented as mean \pm SEM of at least four donors within independent experiments. ${ }^{*}: p \leqslant 0.05 ;{ }^{* *}: p \leqslant 0.01$.

Finally, supernatants of alveolar macrophages infected with S. pneumoniae were used for stimulation of GM-CSF in AEC II in the presence or absence of anakinra to provide evidence for the dependence of epithelial GM-CSF on IL-1 $\beta$ released by alveolar macrophages (figure $3 \mathrm{j}$ ). However, the inhibition of epithelial GM-CSF expression seems not to be restricted to IL- $1 \beta$ suppression in alveolar macrophages alone; instead IFN may also directly inhibit GM-CSF after IL-1 $\beta$ stimulation (online supplementary figure S7).

\section{Tyk2 inhibition restores IAV-induced type I and III IFN-mediated suppression of the IL-1ß- GM-CSF axis and reduces bacterial growth}

To clarify the cellular level, the IFN type responsible and the mechanism of $S$. pneumoniae-induced IL-1 $\beta$ suppression after IAV infection, we first used isolated alveolar macrophages from fresh human lung tissue challenged with bacteria in the absence or presence of type I IFN- $\beta$, type II IFN- $\gamma$ or type III IFN- $\lambda_{1}$. No differences were found on the transcriptional level for IL-1 $\beta$ mRNA expression (figure $4 \mathrm{a}$ ). However, type I IFN significantly suppress pro-IL- $1 \beta$ production and consecutive IL- $1 \beta$ secretion and, to a lower extent so does type III IFN, whereas type II IFN had no suppressive effect, transcriptionally nor translationally (figure $4 \mathrm{~b}$ and c). In comparison to type II IFN, downstream signalling of IFN type I and III include the IFN receptor I and III-associated Tyk2. Therefore, we used the novel available small-molecule competitive Tyk2 inhibitor PRT2070 in alveolar macrophages and human lungs. Tyk2 inhibition completely restored IFN- $\beta$-mediated IL-1 $\beta$ suppression in alveolar macrophages as well as IAV-induced suppression of S. pneumoniae-triggered IL-1 $\beta$ and GM-CSF production in human lungs (figure $5 \mathrm{a}-\mathrm{c}$ ). Moreover, inhibition of Tyk 2 shows a promising reduction of bacterial growth in human lung tissue (figure $5 \mathrm{~d}$ ). 

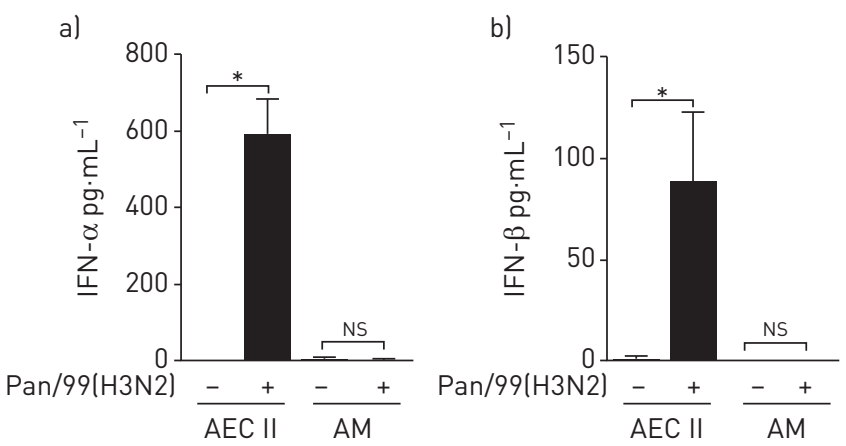

AEC II
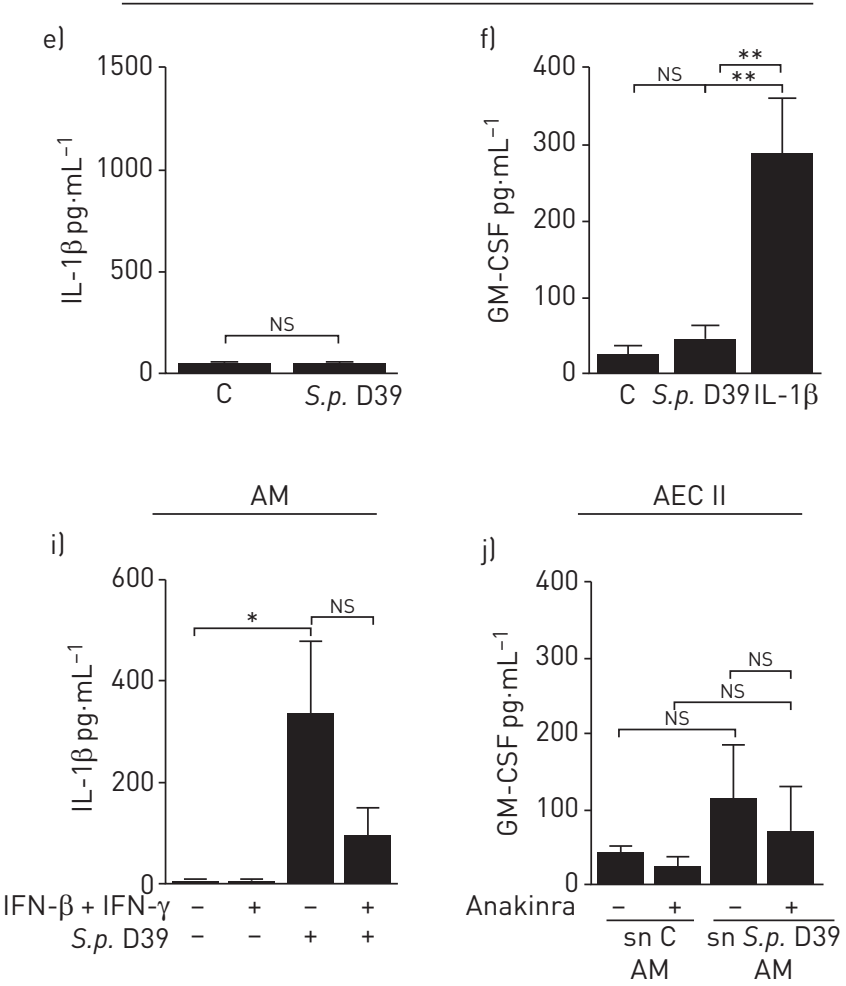

c)

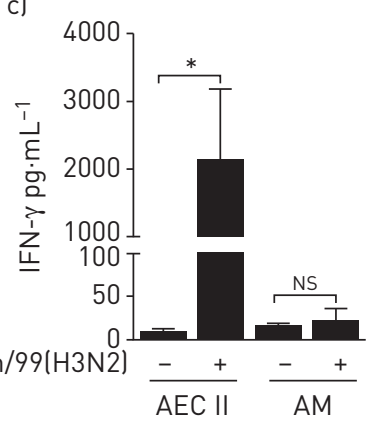

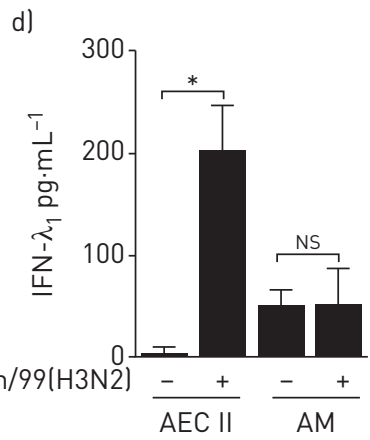

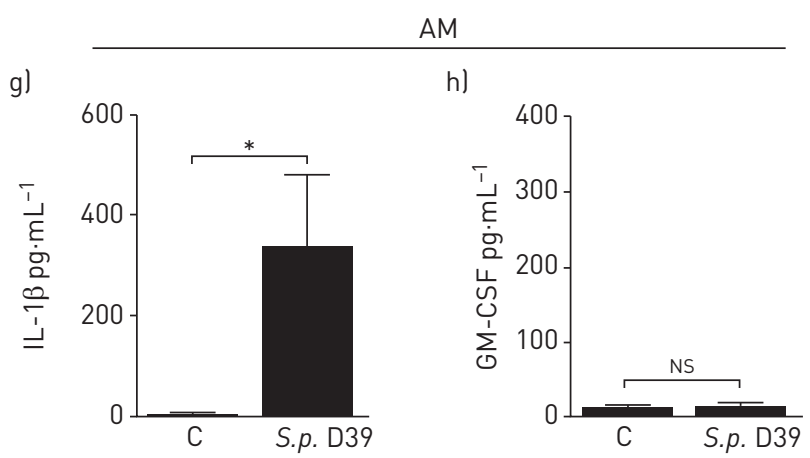

FIGURE 3 Alveolar epithelial type II cells (AEC II) and alveolar macrophages (AM) produce type I, II, and III interferons (IFN) upon influenza A virus Pan/99(H3N2) (IAV) infection, which suppresses AM-induced interleukin (IL)-1 $\beta$ leading to suppression of AEC-produced granulocyte-macrophage colony-stimulating factor (GM-CSF). AEC II and AM, both isolated from fresh human lung tissue, were cultured for either 3-4 days (AEC II) or 2 days (AM). To identify the cellular source of IFN, the release of a) IFN- $\alpha$; b) IFN- $\beta$; c) IFN- $\gamma$; and d) IFN- $\lambda_{1}$ was determined in supernatants of IAV $\left(1 \times 10^{6} \mathrm{PFU} \cdot \mathrm{mL}^{-1} ; 24 \mathrm{~h}\right)$ infected cells compared to mock-infected cells. e) Measurement of IL-1 $\beta$ and f) GM-CSF in AEC II challenged with Streptococcus pneumoniae (S.p.) D39 (1 multiplicity of infection (MOI)) for $16 \mathrm{~h}$. f) Additional stimulation of AEC II with IL-1 3 (5 $\mathrm{ng} \cdot \mathrm{mL}^{-1}$ ) showed induction of GM-CSF in AEC II. g) Measurement of IL-1 $\beta$ and h) GM-CSF in AM challenged with S. pneumoniae (MOI 1) for $16 \mathrm{~h}$. i) AM were mock challenged or stimulated with a combination of IFN- $\beta$ and IFN- $\gamma\left(100 \mathrm{U} \cdot \mathrm{mL}^{-1}\right.$ each) $16 \mathrm{~h}$ before pneumococcal infection and supernatants were assayed for release of IL-1 $\beta$. j) AEC II were treated with anakinra $\left(1 \mathrm{ng} \cdot \mathrm{mL}^{-1}\right)$ or control medium for $4 \mathrm{~h}$. Afterwards cells were incubated for $20 \mathrm{~h}$ with supernatants (sn) obtained from AM challenged with control (C) medium or S. pneumoniae (MOI 1 for 16 h). Supernatants of AEC II were assayed for release of GM-CSF. Data are presented as meanıSEM of at least three donors within independent experiments. NS: nonsignificant. ${ }^{*}: p \leqslant 0.05 ;{ }^{* *}: p \leqslant 0.01$.

\section{Discussion}

The induction of cytokines is essential for the initiation of an adequate innate immune response against viral and bacterial infection. However, in subsequent co-infections the antiviral response might strongly compromise antibacterial defence, leading to inadequate bacterial killing, alveolar damage and finally ARDS [4, 7]. Mouse models have indicated virally induced IFNs as important factors for the modulation of antibacterial actions [5-7, 30]. Nevertheless, the influence of IFN on the antibacterial immune response in human lung tissue is unknown so far, and we therefore used an ex vivo human lung tissue model to address this issue. We revealed a cellular communication by which pneumococci lead to upregulation of 

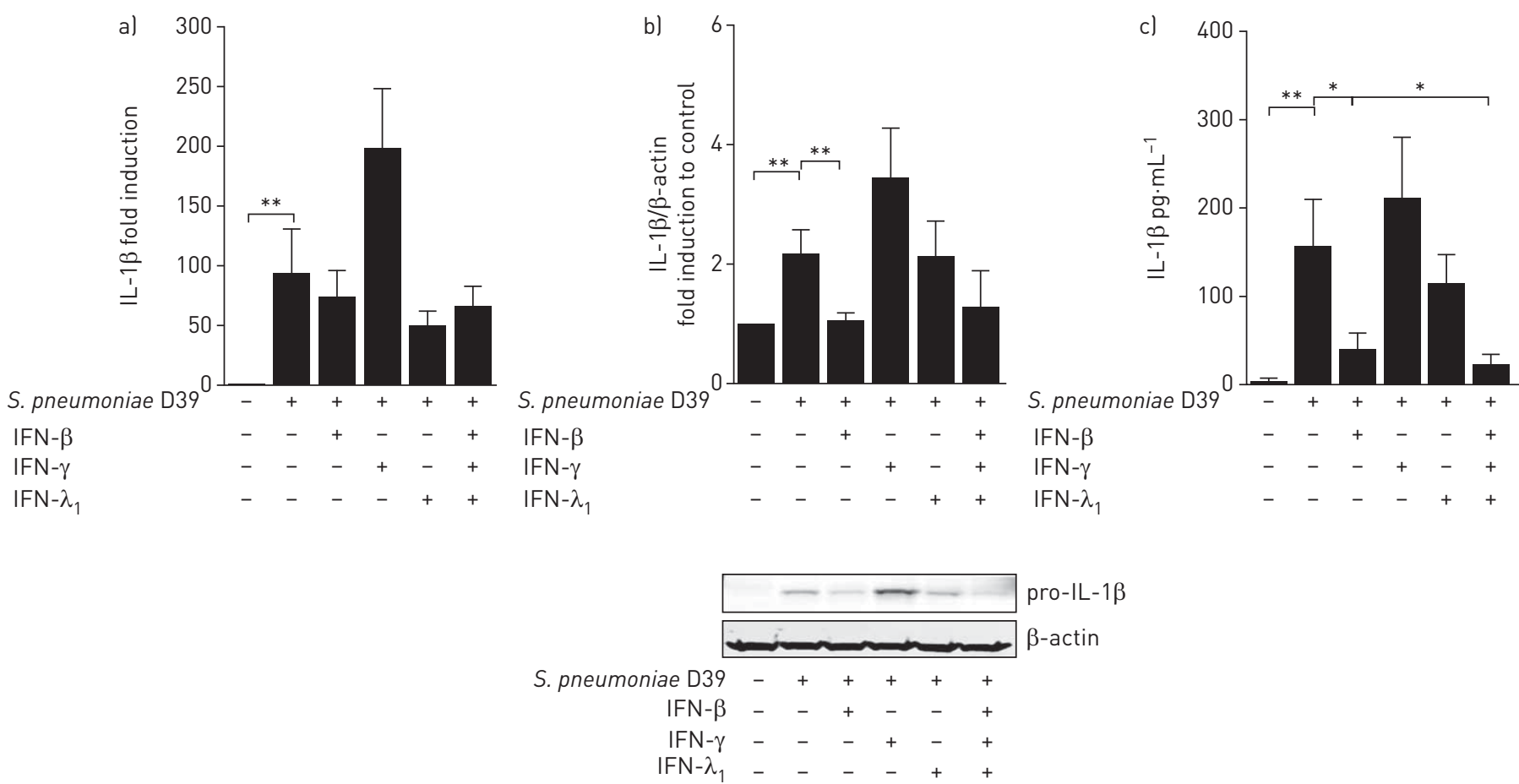

FIGURE 4 Type I interferon (IFN)- $\beta$ is the main suppressor of alveolar macrophage (AM)-induced interleukin (IL)-1 $\beta$ protein expression and secretion. AMs, isolated from fresh human lung tissue, were cultured for 2 days and challenged with type I IFN- $\beta$, type II IFN- $\gamma$, type III IFN- $\lambda_{1}$ or a combination of all three (100 U. $\mathrm{mL}^{-1}$ each) for $16 \mathrm{~h}$. Afterwards, cells were infected with Streptococcus pneumoniae (1 multiplicity of infection). RNA, protein and supernatants were collected $16 \mathrm{~h}$ after pneumococcal infection and assayed for release of a) IL-1 3 mRNA expression; b) pro-IL-1 $\beta$ protein expression; and C) IL-1 $\beta$ secretion. Data are presented as mean \pm SEM of at least six donors within independent experiments. $*: p \leqslant 0.05 ; * *: p \leqslant 0.01$.

alveolar epithelial GM-CSF via alveolar macrophage-secreted IL-1 $\beta$ and demonstrated that type I and III IFN produced by AEC II and alveolar macrophages after IAV infection strongly interfered with that mechanism on the translational level (figure 6a). By pharmacological inhibition of IFN receptor-associated Tyk2 we were able to fully restore the IL-1 $\beta-$ GM-CSF axis and showed beneficial effects on bacterial growth in human lungs (figure 6b).

Induction of IFN in succession to IAV infection is a conserved and indispensable antiviral response in different species such as mice, ferrets, pigs, horses and humans [31]. Although the cellular antiviral effects seem, in principle, to be similar among species, IFNs induce hundreds of additional genes leading to multifaceted secondary immune reactions, our understanding of which is further complicated by species differences of IFN types, which may potentiate this diversity [32]. Since no species other than human suffers from secondary bacterial pneumonia after IAV infection, it seems that the diverse IFN effects significantly contribute to this fatal superinfection. This is strongly supported by studies in mice infected by adapted IAV strains that become susceptible to secondary bacterial pneumonia mediated by influenzainduced type I and II IFN [3-7, 28, 30].

Therefore, we first analysed the IFN response in human lung tissue after infection with the seasonal IAV strain H3N2. In comparison to mouse data showing type I and predominantly type III IFN responses [33], we found that human lung tissue significantly increased members of all IFN types with an emphasis on type II IFN- $\gamma$, which was more than 15 times greater. Interestingly, studies on A549 cells, primary human AECs or even human lung tissue found supporting results for type I and III IFN, but unfortunately neglected the measurement of IFN- $\gamma$ after IAV infection [34-36]. Current understanding allocates the cellular source of type II IFN- $\gamma$ to activated T-lymphocytes and natural killer cells rather than AECs, therefore assuming a role in adaptive immune activation instead of innate antiviral activity [37]. However, in the short-term organ culture model used, adaptive immune reactions and activated T-cells are probably absent, and we identified IAV-infected AEC II and not alveolar macrophages as the cellular source of the strong IFN- $\gamma$ production. The capability of human AEC II to produce IFN- $\gamma$ is in line with a prior study on interstitial lung disease [38]. Whether IFN- $\gamma$ directly exerts antiviral effects in human lungs remains unclear, and should be investigated in future studies. In any case, evidence exists that IAV-induced type I and II IFNs facilitate the susceptibility to secondary pneumococcal infection in mice by diminishing 

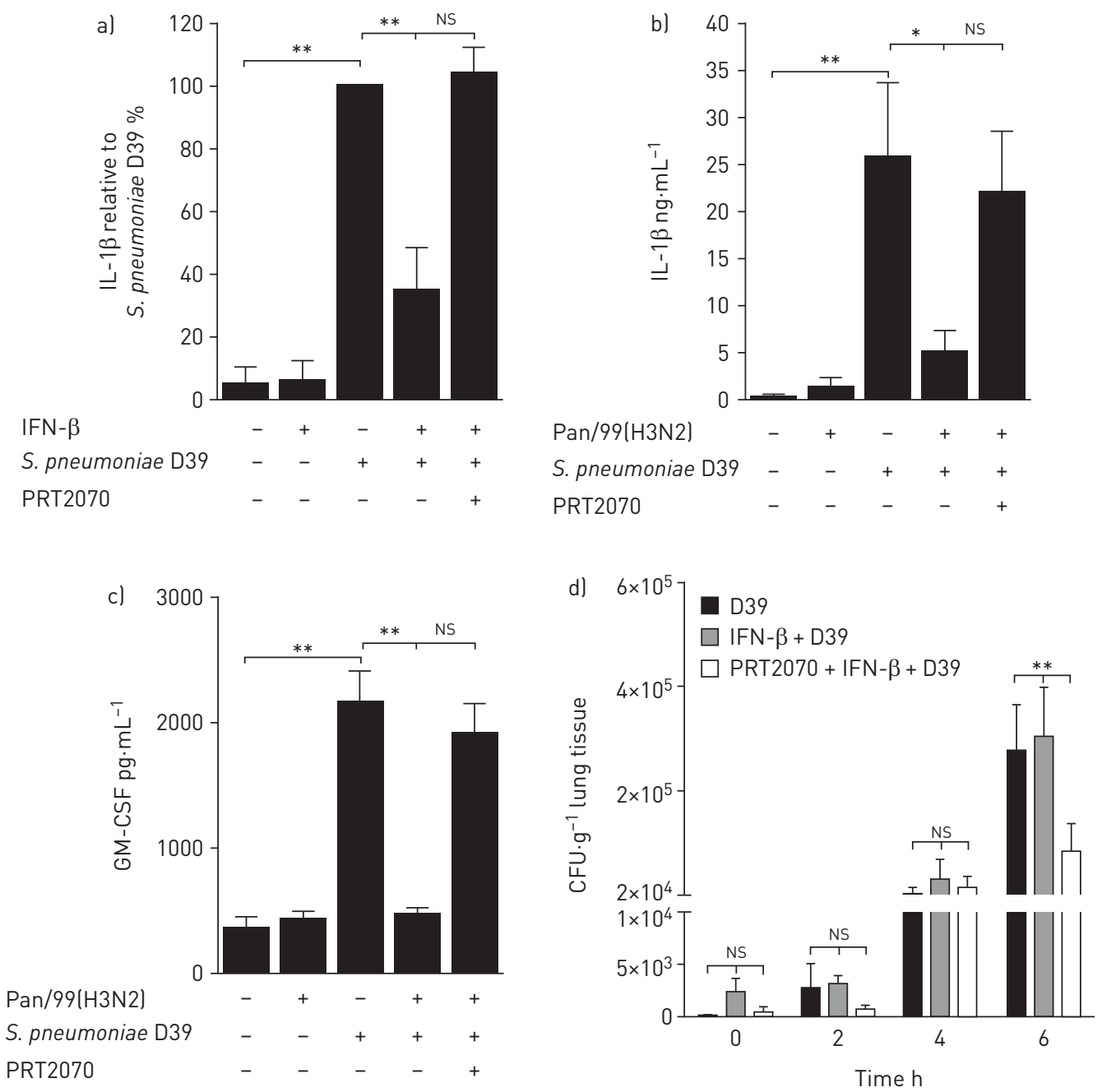

FIGURE 5 Block of type I and III interferon (IFN) signalling with the tyrosine kinase 2 inhibitor PRT2070 rescues Streptococcus pneumoniae D39-induced interleukin (IL)-1 $\beta$ and granulocyte-macrophage colony-stimulating factor (GM-CSF) in alveolar macrophages (AM) and human lung tissue and decreases bacterial growth. a) AMs isolated from fresh human lung tissue were cultured for 2 days and treated with the inhibitor PRT2070 $(1 \mu \mathrm{M})$. Afterwards, cells were challenged with IFN- $\beta\left(100 \mathrm{U} \cdot \mathrm{mL}^{-1}\right)$ for $16 \mathrm{~h}$ and infected with S. pneumoniae (1 multiplicity of infection; $16 \mathrm{~h}$ ) and supernatants were assayed for release of IL-1 $\beta$. b) and c) Lungs were pretreated with PRT2070 $(1 \mu \mathrm{M})$ for $1 \mathrm{~h}$. Indicated lung specimens were challenged with influenza A virus Pan/99(H3N2) (IAV) $\left(1 \times 10^{6} \mathrm{PFU} \cdot \mathrm{mL}^{-1}\right)$ for $24 \mathrm{~h}$ and with S. pneumoniae $\left(1 \times 10^{6} \mathrm{CFU} \cdot \mathrm{mL}^{-1}\right)$ for a further $16 \mathrm{~h}$. Release of b) IL-1 $\beta$ and c) GM-CSF was measured. Data in a) are presented as percentage of S. pneumoniae-treated cells, because of high variations between AM donors for secreted IL-1 $\beta$. Amounts of $\mathrm{IL}-1 \beta$ secretion in $\mathrm{pg} \cdot \mathrm{mL}^{-1}$ are documented in online supplementary table S1. d) Bacterial growth was measured in human lung tissue after $S$. pneumoniae infection, IFN- $\beta$ treatment followed by $S$. pneumoniae infection and pretreatment with PRT2070 $(1 \mu \mathrm{M})$ followed by IFN $-\beta$ and S. pneumoniae. Data are presented as mean \pm SEM of at least five donors within independent experiments. NS: nonsignificant. ${ }^{*}: p \leqslant 0.05 ;{ }^{* *}: p \leqslant 0.01$.

neutrophil recruitment, IL-17-producing $\gamma \delta$ T-cells, chemokines such as keratinocyte chemoattractant (KC) and macrophage-inflammatory protein-2 and bacterial clearance [5-7].

Likewise, we postulate that IFN receptor pathways are important in human IAV infection. Unfortunately, recrutiment of neutrophils or $\gamma \delta \mathrm{T}$-cells is currently impossible to measure in the ex vivo model, since systemic blood flow is missing, but cytokine regulation and comparison between species would give important insight. We therefore investigated the effect on the composition of the S. pneumoniae-induced cytokine milieu, which is a prerequisite for the orchestration of an adequate innate immune response. Interestingly, during viral/bacterial co-infection, cytokines such as IL-6, IL-8, IL-10 or TNF- $\alpha$ were unchanged, whereas in mice SмIтH et al. [28] showed that the same factors ( $\mathrm{KC}$ as an IL-8 analogue) even increased under co-infection. Additionally, the same effect was found for IL-1 $\beta$ expression, and HeNNET et al. [39] demonstrated upregulation of GM-CSF after IAV challenge. Intriguingly, for the human alveolus 


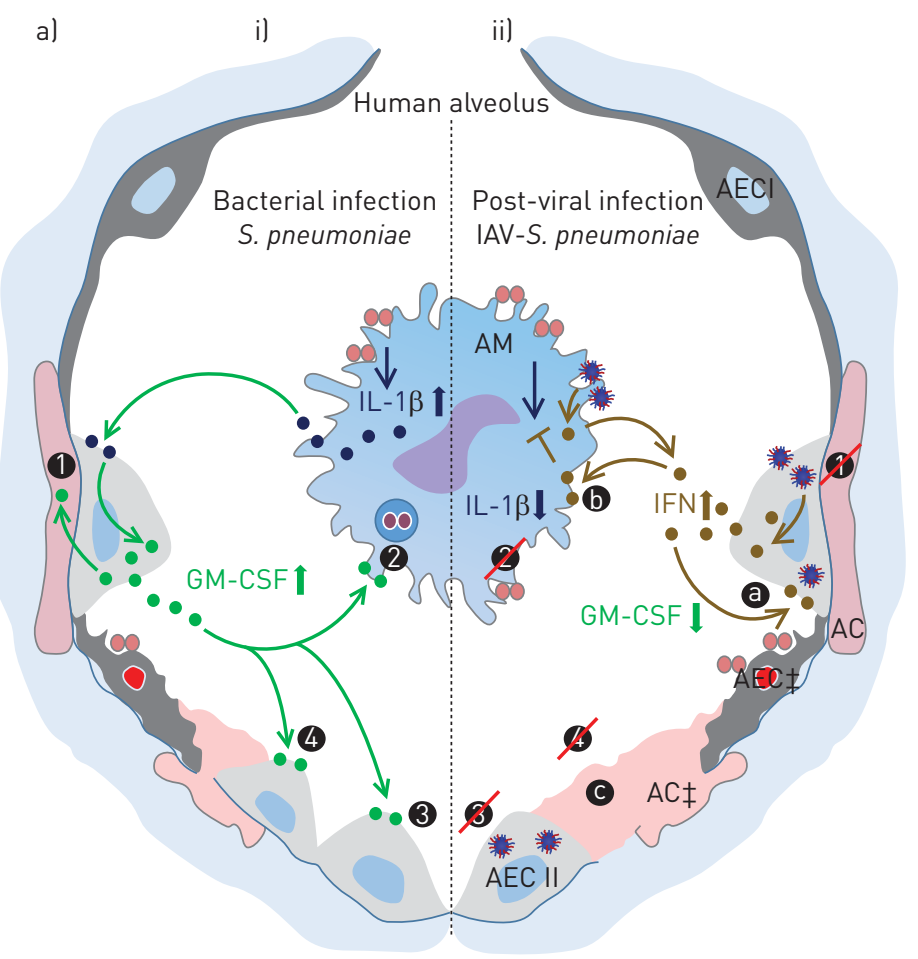

b)

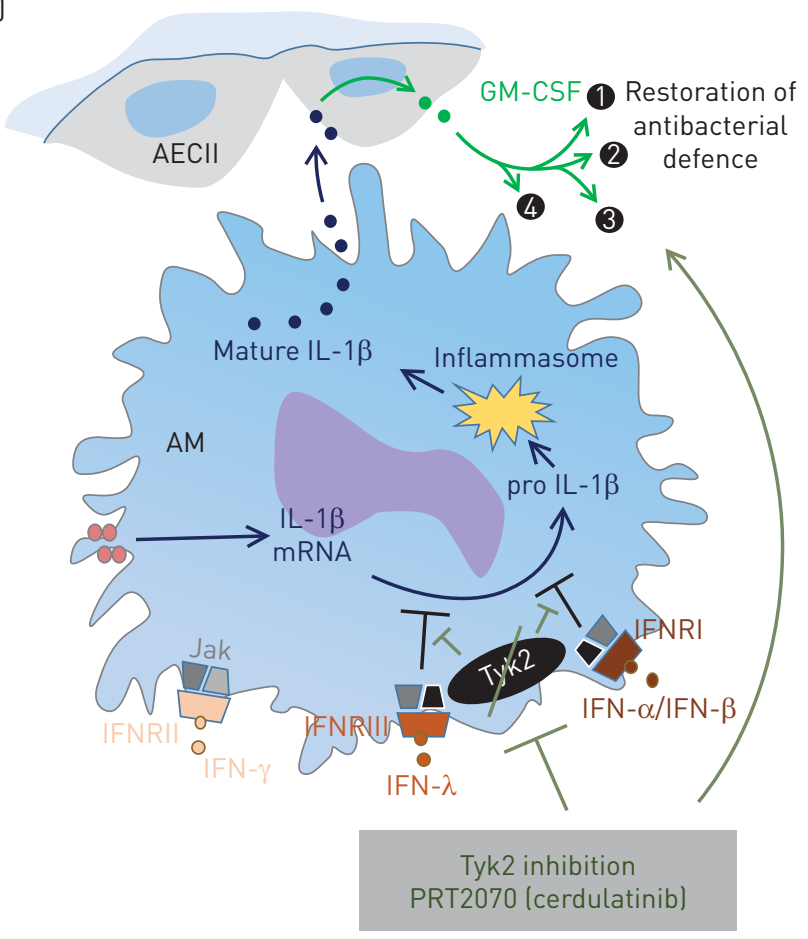

\begin{tabular}{|c|c|}
\hline$\infty$ & S. pneumoniae \\
\hline 畨 & IAV \\
\hline$\bullet$ & IL-1 $\beta$ \\
\hline • & GM-CSF \\
\hline ০๑ & IFN \\
\hline $\boldsymbol{\Delta}$ & Tyk2 \\
\hline $\bar{\square}$ & Jak \\
\hline$\ddagger$ & Damaged \\
\hline
\end{tabular}

(1) Immune cell recruitment

(2) Phagocytosis

(3) Surfactant homeostasis

(4) Proliferation and repair

a Antiviral activity

b Immune modulation

C Strong alveolar damage and loss of repair

FIGURE 6 a) Proposed model for the cellular interplay controlled by the early cytokine response in the human alveolus under i) single bacterial or ii) viral and bacterial co-infection. In i) Streptococcus pneumoniae is recognised by alveolar macrophages (AM) releasing inflammasome-dependent interleukin (IL)-1 $\beta$, which serves as driving factor for granulocyte-macrophage colony-stimulating factor (GM-CSF) production in alveolar epithelial type II cells (AECII). GM-CSF probably supports the inflammatory reaction by contribution to immune cell recruitment, phagocytic function and surfactant homeostasis, as well as the initiation of proliferation and repair processes. In ii), the pre-infection with influenza A virus initiates an antiviral interferon (IFN) response, which subsequently blocks IL-1 $\beta$ and GM-CSF expression, thereby reducing protective GM-CSF effects and promoting alveolar damage. b) Inhibition of tyrosine kinase 2 (Tyk2) with PRT2070 (cerdulatinib) restores the influenza A virus Pan/99(H3N2) (IAV)-induced and IFN type I- and III-mediated impairment of the antibacterial immune response. Jak: Janus kinases; AC: alveolar capillary; IFNR: IFN receptor.

we revealed a difference, since IAV neither increased IL-1 $\beta$ nor GM-CSF, but significantly inhibited these factors under pneumococcal infection, which points towards a species-specific mechanism for the pathogenesis of human lung co-infection.

The importance of IL-1 $\beta$ has been demonstrated in a mouse co-infection model with IAV and $S$. aureus and during pneumococcal pneumonia, but its impact, and in particular its strong downregulation in human lung tissue by IAV infection, is unclear so far $[11,12]$. Previous studies have indicated that IFN can inhibit IL-1 $\beta$ production at different levels dependent on species or cell type [8-10, 40, 41]. We therefore replaced IAV by IFN- $\beta$ and IFN- $\gamma$ pretreatment and found a similar expression pattern, with significant IL-1 $\beta$ and GM-CSF reduction in human lungs.

In addition to IL-1 $\beta$, several studies have demonstrated a considerable role of GM-CSF in the outcome of pulmonary infections with IAV or pneumococcal pneumonia and the first clinical trials using GM-CSF as an adjunctive treatment have been introduced [15-17, 19-23, 42, 43]. This emphasises the importance of elucidating its regulation directly in human lung tissue, especially under viral/bacterial co-infection, where a deregulated immune reaction may significantly contribute to fatal outcome.

GM-CSF may be induced by different stimuli, and in mice lungs CAKAROva et al. [29] revealed TNF- $\alpha$ to be the responsible mediator after lipopolysaccharide stimulation. However, the regulation of GM-CSF in 
mouse AECs is not fixed to TNF- $\alpha$, and seems to depend on cellular origin and culture conditions, determining the phenotypic characteristics. The study by Mir-Kasimov et al. [44] has demonstrated that GM-CSF in in vitro mouse AECs can be induced by both TNF- $\alpha$ and IL- $1 \beta$, demonstrating the importance of validating such results in the human context. In human lungs the cellular source, as well as the driving factor is so far unknown. Either direct pneumococcal Toll-like receptor activation or secondary cytokine-mediated effects may cause GM-CSF expression. Our experiments on intact human lung tissue, isolated primary AECs and alveolar macrophages using anakinra as a specific IL-1 receptor antagonist demonstrated an indirect pneumococcal mechanism in which alveolar macrophages derived IL-1 $\beta$ - rather than TNF- $\alpha$-fostered AEC II dependent GM-CSF induction. This was further supported by our observation that in co-infection conditions, TNF- $\alpha$ is still present and TNF- $\alpha$ stimulation alone was not sufficient to induce GM-CSF.

In contrast to the induction of GM-CSF, its suppression in AEC II is also of particular interest, since IFNs have been shown to directly inhibit IL-1 $\beta$-induced GM-CSF in human retinal epithelial or bone marrow cells $[13,45]$. We therefore demonstrated that next to IL-1 receptor blockade, IFN treatment in the presence of IL- $1 \beta$ suppressed GM-CSF in lungs, meaning that IFNs act on both alveolar macrophage IL-1 $\beta$ production and on secondary IL-1 $\beta$-induced epithelial GM-CSF expression.

Our results show a distinct cellular communication mechanism in the human alveolus, where alveolar macrophages are activated by $S$. pneumoniae to produce IL-1 $\beta$, which then triggers epithelial GM-CSF production. This signalling cascade is repressed by preceding IAV infection. Once more, GM-CSF has shown to be crucial in lung infection [15-21] and is now considered for treatment in acute lung injury and ARDS $[22,23]$. Therefore, we aimed to find an immune modulatory intervention strategy to restore the antibacterial GM-CSF response. A systematic analysis was performed to reveal the responsible IFN types as well as the cellular level of IL-1 $\beta$ inhibition, and found that type I and III IFN blocks the translation of pro-IL-1 $\beta$. Treatment of mice with type I IFN was shown to lead to an increased IAV-induced mortality due to strong proinflammatory immune cell activation [46]. Compared to type II IFN receptors, type I and III receptors signal underinvolvement of Tyk2, which has already been shown to control IL-1 $\beta$ expression in a signal transducer and activator of transcription 1-dependent manner in murine macrophages [47]. Several clinical trials targeting Tyk2 are under way in patients suffering from immunological and inflammatory disorders [48], but it is unknown whether this intervention might be helpful in lung infections, particularly in severe viral/bacterial pneumonia. Here we show that use of the pharmacological Tyk2 inhibitor (PRT2070) fully restored pneumococcal-induced alveolar macrophages IL-1 $\beta$ and finally epithelial GM-CSF after IAV infection in human lung co-infection. This is of particular interest with regard to clinical trials in pneumonia-associated ARDS patients receiving GM-CSF treatment. The systemic administration in the trial by PAINE et al. [23] did not reveal significant effects, but a first compassionate inhalative application with a low number of cases by HerolD et al. [22] showed positive tendencies of pulmonary host defence modulation. If GM-CSF treatment were successful, compared to IFN receptor pathway inhibition, fewer adverse effects are likely. However, if one single factor such as GM-CSF is not sufficient to restore the entire pulmonary host defence against secondary bacterial pneumonia, an early IFN receptor pathway modulation with, for example, clinically developed Tyk2 inhibitors would offer a further promising approach, since we not only restored endogenous GM-CSF, but also demonstrated a benficial effect of Tyk2 inhibition on reduction of bacterial growth.

Taken together, our results demonstrated for the first time the human lung tissue model as suitable for the characterisation of innate immune events in IAV and S. pneumoniae co-infection. Due to the absence of systemic leukocyte recruitment and adaptive immunity, it becomes possible to discriminate alveolus-specific regulation to model the underlying cellular interplay between alveolar macrophages and AECs controlled by early cytokines.

It has to be stressed that most of the tissue is recruited from lung cancer patients having a history of smoking and chronic obstructive pulmonary disease (COPD) as a comorbidity. Therefore, the peripheral normal lung tissue used cannot be assigned as completely healthy. However, smoking contributes to the major identified risk factors for community-acquired pneumonia (CAP), and patients with COPD have a two- to four-fold higher risk of developing CAP and severe IAV-associated pneumococcal infection [49-51]. This is reflected in large CAP cohorts that demonstrate that a quarter to one-third of hospitalised patients suffer from COPD [52]. Thus, we would not categorise smoking as a limitation of the model, but rather as a very relevant aspect, and we argue that the patients from whom we acquired the tissue are at higher risk of $\mathrm{CAP}$ and can be considered a relevant group of interest.

An additional benefit of human lung tissue in comparison to mouse models is that the human lung tissue can be directly infected with viral and bacterial strains isolated from infected patients, which therefore strengthens the relevance of the data. The disclosure of immune differences between mice and humans, as 
shown in this study, is of particular importance, since factors such as GM-CSF are already used in clinical trials and considered for immune modulatory treatment in acute lung injury. Moreover, we suggest pharmacological Tyk2 inhibition as an immune modulatory intervention strategy to sustain the crucial endogenous GM-CSF levels in severe viral/bacterial pneumonia.

\section{Acknowledgements}

Parts of this work are included in the doctoral thesis of Johanna Berg. We are grateful to Katharina Hellwig and Doris Stoll (Charité - Universitätmedizin Berlin, Berlin, Germany) for technical assistance. The authors thank Thorsten Wolff (Robert Koch-Institut, Berlin, Germany), for providing influenza A virus H3N2. Streptococcus pneumoniae D39 serotype 2 was kindly provided by Sven Hammerschmidt (University of Greifswald, Greifswald, Germany. The clinical isolate serotype 3 was kindly provided by Mark van der Linden (National Reference Center for Streptocooci, Aachen, Germany).

\section{References}

1 Austrian R, Gold J. Pneumococcal bacteremia with especial reference to bacteremic pneumococcal pneumonia. Ann Intern Med 1964; 60: 759-776.

2 Ewig S, Birkner N, Strauss R, et al. New perspectives on community-acquired pneumonia in 388406 patients. Results from a nationwide mandatory performance measurement programme in healthcare quality. Thorax 2009; 64: 1062-1069.

3 Smith AM, McCullers JA. Secondary bacterial infections in influenza virus infection pathogenesis. Curr Top Microbiol Immunol 2014; 385: 327-356.

4 Robinson KM, Kolls JK, Alcorn JF. The immunology of influenza virus-associated bacterial pneumonia. Curr Opin Immunol 2015; 34: 59-67.

5 Shahangian A, Chow EK, Tian X, et al. Type I IFNs mediate development of postinfluenza bacterial pneumonia in mice. J Clin Invest 2009; 119: 1910-1920.

6 Li W, Moltedo B, Moran TM. Type I interferon induction during influenza virus infection increases susceptibility to secondary Streptococcus pneumoniae infection by negative regulation of $\gamma \delta \mathrm{T}$ cells. J Virol 2012; 86: 12304-12312.

7 Sun K, Metzger DW. Inhibition of pulmonary antibacterial defense by interferon- $\gamma$ during recovery from influenza infection. Nat Med 2008; 14: 558-564.

8 Eigenbrod T, Bode KA, Dalpke AH. Early inhibition of IL-1 $\beta$ expression by IFN- $\gamma$ is mediated by impaired binding of NF- $\mathrm{KB}$ to the IL-1 $\beta$ promoter but is independent of nitric oxide. J Immunol 2013; 190 : 6533-6541.

9 Guarda G, Braun M, Staehli F, et al. Type I interferon inhibits interleukin-1 production and inflammasome activation. Immunity 2011; 34: 213-223.

10 Masters SL, Mielke LA, Cornish AL, et al. Regulation of interleukin-1 $\beta$ by interferon- $\gamma$ is species specific, limited by suppressor of cytokine signalling 1 and influences interleukin-17 production. EMBO Rep 2010; 11: 640-646.

11 Kafka D, Ling E, Feldman G, et al. Contribution of IL-1 to resistance to Streptococcus pneumoniae infection. Int Immunol 2008; 20: 1139-1146.

12 Robinson KM, Choi SM, McHugh KJ, et al. Influenza A exacerbates Staphylococcus aureus pneumonia by attenuating IL-1 $\beta$ production in mice. J Immunol 2013; 191: 5153-5159.

13 Aman MJ, Keller U, Derigs G, et al. Regulation of cytokine expression by interferon- $\alpha$ in human bone marrow stromal cells: inhibition of hematopoietic growth factors and induction of interleukin-1 receptor antagonist. Blood 1994; 84: 4142-4150.

14 Göllner G, Aman MJ, Steffens HP, et al. Interferon- $\alpha$ (IFN- $\alpha$ ) inhibits granulocyte-macrophage colony-stimulating factor (GM-CSF) expression at the post-transcriptional level in murine bone marrow stromal cells. Br J Haematol 1995; 91: 8-14

15 Huang FF, Barnes PF, Feng Y, et al. GM-CSF in the lung protects against lethal influenza infection. Am J Respir Crit Care Med 2011; 184: 259-268.

16 Huang $\mathrm{H}$, Li $\mathrm{H}$, Zhou $\mathrm{P}$, et al. Protective effects of recombinant human granulocyte macrophage colony stimulating factor on H1N1 influenza virus-induced pneumonia in mice. Cytokine 2010; 51: 151-157.

17 Sever-Chroneos Z, Murthy A, Davis J, et al. GM-CSF modulates pulmonary resistance to influenza A infection. Antiviral Res 2011; 92: 319-328.

18 Unkel B, Hoegner K, Clausen BE, et al. Alveolar epithelial cells orchestrate DC function in murine viral pneumonia. J Clin Invest 2012; 122: 3652-3664.

19 LeVine AM, Reed JA, Kurak KE, et al. GM-CSF-deficient mice are susceptible to pulmonary group B streptococcal infection. J Clin Invest 1999; 103: 563-569.

20 Standiford LR, Standiford TJ, Newstead MJ, et al. TLR4-dependent GM-CSF protects against lung injury in Gram-negative bacterial pneumonia. Am J Physiol Lung Cell Mol Physiol 2012; 302: L447-L454.

21 Steinwede K, Tempelhof O, Bolte K, et al. Local delivery of GM-CSF protects mice from lethal pneumococcal pneumonia. I Immunol 2011; 187: 5346-5356.

22 Herold S, Hoegner K, Vadász I, et al. Inhaled granulocyte/macrophage colony-stimulating factor as treatment of pneumonia-associated acute respiratory distress syndrome. Am J Respir Crit Care Med 2014; 189: 609-611.

23 Paine R, Standiford TJ, Dechert RE, et al. A randomized trial of recombinant human granulocyte-macrophage colony stimulating factor for patients with acute lung injury. Crit Care Med 2012; 40: 90-97.

24 Hocke AC, Becher A, Knepper J, et al. Emerging human Middle East respiratory syndrome coronavirus causes widespread infection and alveolar damage in human lungs. Am J Respir Crit Care Med 2013; 188: 882-886.

25 Elbert KJ, Schäfer UF, Schäfers HJ, et al. Monolayers of human alveolar epithelial cells in primary culture for pulmonary absorption and transport studies. Pharm Res 1999; 16: 601-608.

26 Weinheimer VK, Becher A, Tönnies M, et al. Influenza A viruses target type II pneumocytes in the human lung. J Infect Dis 2012; 206: 1685-1694.

27 Szymanski KV, Toennies M, Becher A, et al. Streptococcus pneumoniae-induced regulation of cyclooxygenase-2 in human lung tissue. Eur Respir J 2012; 40: 1458-1467.

28 Smith MW, Schmidt JE, Rehg JE, et al. Induction of pro- and anti-inflammatory molecules in a mouse model of pneumococcal pneumonia after influenza. Comp Med 2007; 57: 82-89. 

granulocyte-macrophage colony-stimulating factor: impact on alveolar epithelial repair. Am J Respir Crit Care Med 2009; 180: 521-532.

30 Lee B, Robinson KM, McHugh KJ, et al. Influenza-induced type I interferon enhances susceptibility to Gram-negative and Gram-positive bacterial pneumonia in mice. Am J Physiol Lung Cell Mol Physiol 2015; 309: L158-L167.

31 Van Reeth K. Cytokines in the pathogenesis of influenza. Vet Microbiol 2000; 74: 109-116.

32 Platanias LC. Mechanisms of type-I- and type-II-interferon-mediated signalling. Nat Rev Immunol 2005; 5: 375-386.

33 Jewell NA, Cline T, Mertz SE, et al. Lambda interferon is the predominant interferon induced by influenza A virus infection in vivo. J Virol 2010; 84: 11515-11522.

$34 \mathrm{Wu}$ W, Zhang W, Duggan ES, et al. RIG-I and TLR3 are both required for maximum interferon induction by influenza virus in human lung alveolar epithelial cells. Virology 2015; 482: 181-188.

35 Sutejo R, Yeo DS, Myaing MZ, et al. Activation of type I and III interferon signalling pathways occurs in lung epithelial cells infected with low pathogenic avian influenza viruses. PLoS One 2012; 7: e33732.

36 Wu W, Zhang W, Booth JL, et al. Influenza A(H1N1)pdm09 virus suppresses RIG-I initiated innate antiviral responses in the human lung. PLoS One 2012; 7: e49856.

37 Killip MJ, Fodor E, Randall RE. Influenza virus activation of the interferon system. Virus Res 2015; 209 : 11-22.

38 Wallace WA, Howie SE. Immunoreactive interleukin 4 and interferon- $\gamma$ expression by type II alveolar epithelial cells in interstitial lung disease. J Pathol 1999; 187: 475-480.

39 Hennet T, Ziltener HJ, Frei K, et al. A kinetic study of immune mediators in the lungs of mice infected with influenza A virus. J Immunol 1992; 149: 932-939.

40 Chujor CS, Klein L, Lam C. Selective inhibition of interleukin-1 $\beta$ gene expression in activated RAW 264.7 macrophages by interferon- $\gamma$. Eur J Immunol 1996; 26: 1253-1259.

41 De Boer ML, Hu J, Kalvakolanu DV, et al. IFN- $\gamma$ inhibits lipopolysaccharide-induced interleukin-1 $\beta$ in primary murine macrophages via a Stat1-dependent pathway. J Interferon Cytokine Res 2001; 21: 485-494.

42 Quinton LJ. GM-CSF: a double dose of protection during pneumonia. Am J Physiol Lung Cell Mol Physiol 2012; 302: L445-L446.

43 Subramaniam R, Hillberry Z, Chen H, et al. Delivery of GM-CSF to protect against influenza pneumonia. PLoS One 2015; 10: e0124593.

44 Mir-Kasimov M, Sturrock A, McManus M 3rd, et al. Effect of alveolar epithelial cell plasticity on the regulation of GM-CSF expression. Am J Physiol Lung Cell Mol Physiol 2012; 302: L504-L511.

45 Crane IJ, Wallace CA, Forrester JV. Regulation of granulocyte-macrophage colony-stimulating factor in human retinal pigment epithelial cells by IL-1 $\beta$ and IFN- $\gamma$. Cell Immunol 2001; 209: 132-139.

46 Davidson S, McCabe TM, Crotta S, et al. IFN $\lambda$ is a potent anti-influenza therapeutic without the inflammatory side effects of IFN $\alpha$ treatment. EMBO Mol Med 2016; 8: 1099-1112.

47 Radwan M, Stiefvater R, Grunert T, et al. Tyrosine kinase 2 controls IL-1 $\beta$ production at the translational level. $J$ Immunol 2010; 185: 3544-3553.

48 Menet CJ. Toward selective TYK2 inhibitors as therapeutic agents for the treatment of inflammatory diseases. Pharm Pat Anal 2014; 3: 449-466.

49 Mallia P, Johnston SL. Influenza infection and COPD. Int J Chron Obstruct Pulmon Dis 2007; 2: 55-64.

50 Sehatzadeh S. Influenza and pneumococcal vaccinations for patients with chronic obstructive pulmonary disease (COPD): an evidence-based review. Ont Health Technol Assess Ser 2012; 12: 1-64.

51 Torres A, Peetermans WE, Viegi G, et al. Risk factors for community-acquired pneumonia in adults in Europe: a literature review. Thorax 2013; 68: 1057-1065.

52 Müllerova H, Chigbo C, Hagan GW, et al. The natural history of community-acquired pneumonia in COPD patients: a population database analysis. Respir Med 2012; 106: 1124-1133. 